\section{A primeira experiência com o Absolutismo na Espanha}

\section{Miguel Dantas da Cruz [*]}

[*] Investigador de pós-doutoramento no Instituto de Ciências Sociais da Universidade de Lisboa - Portugal.

E-mail miguel.cruz@ics.ulisboa.pt

ORCID: https://orcid.org/0000-0001-7466-3251

Precioso Izquierdo, Francisco, Melchor

Macanaz. La derrota de un "héroe". Poder político y movilidad familiar en la España Moderna, Madrid, Cátedra, 2017, $439 p$.
Resumo: A Guerra da Sucessão da Espanha teve um grande impacto na história política do país ibérico. Tratou-se de um processo traumático, com desdobramentos bem atuais, como se verificou recentemente na Catalunha. O livro aqui resenhado explora o início desse processo, centrando-se na atividade política e na vida de Melchor Macanaz, um dos principais ministros de Felipe V. O autor de iniciativas que enfraqueciam autonomias e reforçavam o poder o rei fez muitos inimigos, que o afastaram do poder e mesmo do território espanhol. A sua imagem seria, mais tarde, recuperada e instrumentalizada em função de conveniências políticas.

Palavras-chave: Absolutismo; Guerra da Sucessão da Espanha; Reformas Bourbônicas; Grupos intermédios; Usos da Memória.

\section{The first Spanish experience with Absolutism}

Abstract: The War of Spanish Succession had a profound impact on the political history of the Iberian country. It was a traumatic process, with ongoing effects, as we could see recently in Catalonia. The book reviewed here explores the beginning of this process, focusing on the political activity and life of Melchor Macanaz, one of the leading ministers of Philip V. As the author of several initiatives that weakened regional autonomies and strengthened royal power, Macanaz made multiple enemies, who overthrew him from power and drove him away from Spain. His memory would later be retrieved and politically used.

Keywords: Absolutism; War of the Spanish Succession; Bourbon Reforms; Intermediate groups; Uses of Memory. 
É difícil, senão mesmo impossível, escrever sobre a história política da Espanha do século XVIII sem falar de Melchor Rafael de Macanaz. Trata-se de um personagem de importância decisiva para compreender as primeiras reformas dos Bourbon no país ibérico e cujo trajeto tem retomado um lugar central na agenda historiográfica espanhola. Por essa razão, o estudo de Francisco Precioso Izquierdo dá assim sequência a um conjunto de trabalhos centrados no famoso fiscal geral do Conselho de Castela, expondo o significado político, intelectual, jurídico e reformista de Macanaz. Atitude corajosa e digna de registro do jovem investigador que não se amedrontou com a tarefa de revisitar uma figura cujo protagonismo histórico, esquadrinhado ao pormenor, é bem conhecido do público académico. Francisco Precioso não pôs o pé em ramo verde. Com origem na sua tese de doutoramento, Melchor Macanaz: La derrota de un "héroe" é estudo minucioso e bem suportado. Francisco Precioso socorre-se de fontes que permaneciam grandemente esquecidas para preencher as lacunas na vida do importante ministro de Felipe V. Outros materiais igualmente originais, consultados por ele em mais de duas dezenas de arquivos, serviram para apontar uma nova luz aos momentos-chave do ciclo político de Macanaz.

Honesto, mas ambicioso e imaginativo, o estudo recorre a metodologias que não costumamos ver juntas numa mesma obra, como são os casos da análise lexicográfica e da prosopografia. O autor é também cuidadoso no tratamento da bibliografia, com a qual dialoga permanentemente. Apesar do que se faz notar no proémio, a obra não corresponde exatamente a uma biografia - e aqui haverá uma ligeira tensão entre o que se anuncia e o que se realiza. Melchor Macanaz é a figura central, mas não é a única. Ao invés, o autor resgata o percurso da família Macanaz na longa duração. Sem dúvida, uma solução muito mais pertinente para a grande problemática do estudo: a mobilidade social da "gente média" na Espanha moderna.

O enfoque na trajetória da família e na relação de várias gerações da família com o poder político é bem visível na organização dos conteúdos. De resto, o autor começa por seguir a consolidação gradual dos Macanaz na vila murciana de Hellín ainda durante as décadas iniciais do século XVII. Ligados à administração local, os Macanaz estavam, contudo, muito longe ser um verdadeiro potentado. Outras famílias mais acaudaladas desempenhavam esse papel. Francisco Precioso não fica porém completamente refém dos Macanaz. A busca das origens desta família é uma oportunidade para se visitar e discutir tópicos tradicionais da historiografia dedicada ao estudo dos modelos de reprodução social no Antigo Regime, o que o autor faz com maestria, ou não tivesse sido orientado pelos grandes especialistas Francisco Chacón Jiménez e Juan Hernández-Franco. Num certo sentido, o percurso dos Macanaz tipifica uma trajetória social ascendente do período. Nele encontramos as tradicionais estratégias matrimonias criteriosamente levadas a cabo, e a acumulação de patrimônio, que o autor reconstitui e que estava inevitavelmente destinado à constituição de um morgadio. Nele encontramos também os esforços destinados a provar a antiga linhagem fidalga da família, entretanto caída em desgraça, mas que não deixava de reclamar uma 
folha de serviços que recuaria ao século XI. Sobre a família pairou ainda a proverbial acusação de mácula de sangue, de modo algum invulgar naquele período. Alguns dos antepassados de Melchor, da parte materna, seriam conversos, originalmente expulsos de Castela pelos reis católicos, mas regressados em 1580.

A passagem pela universidade era também - era cada vez mais - um atributo dos membros da administração central espanhola, e Melchor Macanaz não foi diferente. A passagem pelas universidades de Valência e Salamanca, onde se formou em Leis e Cânones, terá sido inclusivamente decisiva para a formação intelectual do jovem Melchor. Aí foi exposto à literatura arbitrista do século XVII de forte pendor regalista. Aí terá sido também confrontado com um sistema de ensino dominado pelos Colégios Maiores, em detrimento dos estudantes menos privilegiados como Melchor. Como já foi notado por outro biografo seu, a inspiração para futuras propostas de reforma das instituições universitárias pode ser encontrada nesse ressentimento juvenil (Martín, 1982, p. 29-31). Igualmente importante para a formação do murciano foi a sua ligação à Casa dos marqueses de Villena, onde participou em reuniões e tertúlias. Na verdade, esta Casa aristocrática providenciaria ainda a experiência burocrática indispensável ao jovem advogado, que, entretanto, passara a gerir os negócios do oitavo marquês. Outras casas desempenharam papel semelhante de alfobre de futuros administradores. A grande nobreza, como poder de implantação regional, assegurava a ligação entre elites locais e o poder central.

A segunda parte constitui núcleo principal do livro. Duas centenas de páginas cobrem o essencial do ciclo de vida e do ciclo político de Melchor, a começar pela sua cooptação pela nova dinastia bourbônica, que muito rapidamente começou a proceder a alterações nas práticas governativas da Monarquia. Destacam-se, a esse respeito, a restruturação dos ofícios da Casa Real, o recrutamento de burocratas em Versalhes e a constituição da Guardia de Corps, um novo corpo militar para a Corte de Felipe V - tudo para desagrado da aristocracia espanhola. Integrado num conhecido processo de renovação de quadros administrativos (Dedieu, 2002, p. 381-399), Melchor alcançou grande notoriedade pela forma intransigente como procedeu à repressão de austracistas — partidários do arquiduque Carlos de Habsburgo - , primeiro em Valencia e depois em Aragão. Esses reinos tinham-se virado contra Felipe V, apesar de o neto de Luís XIV ter jurado defender as "constituições políticas" da Coroa de Aragão.

As causas do realinhamento aragonês não se prendiam exclusivamente com o receio do reforço do poder absoluto do monarca, acrescentado em prejuízo das autonomias locais, ainda que isso fosse fundamental. Por exemplo, na Catalunha rural, a presença de tropas bourbônicas esteve longe de ser uma medida inócua, provocando grande descontentamento entre aqueles que se lembravam das incursões recentes dos exércitos de Luís XIV. A isso se juntava também a existência de uma elite mercantil, sobretudo na cidade de Barcelona, comercialmente ligada à Inglaterra e à Holanda e muito arredia aos interesses franceses. 
Pela sua infidelidade, a Coroa de Aragão seria exemplarmente castigada por via da desqualificação de suas instituições. A Nova Planta (1707), legitimada no direito de conquista que, em teoria, libertava o monarca de constrangimento jurisdicionais, suprimiu as Cortes de Aragão, e com elas boa parte da autonomia política do território. A isso se deve juntar o desmembramento do Conselho de Aragão e a criação, não de uma chancelaria - instituição mais elevada - , mas de uma mera audiência, subordinada ao Conselho de Castela. Entretanto, o tradicional vice-rei, um verdadeiro alter ego do rei, daria lugar a um capitão-general, que, na prática, era um militar ao qual se delegava o poder absoluto do monarca. Tudo no quadro de uma gradual militarização da administração do território - uma novidade absoluta em Espanha (Ruiz, 2008, p. 39-40).

A solução adotada, que esteve longe de recolher unanimidade em Castela, recebeu um importante contributo do regalista Macanaz. O ministro beneficiava então da proteção das principais figuras do regime, a começar pelo embaixador francês Amelot e pelo confessor de Felipe V, Robinet. Em 1713, seria nomeado para o lugar de fiscal geral do Conselho de Castela, a partir do qual lançou um ambicioso plano de reformas de algumas das principais instituições espanholas. A "planta de Macanaz", como então ficou conhecida, visava remodelar os conselhos de Castela, Fazenda, Índias e Ordens e, posteriormente, o de Guerra e da Inquisição. O propósito era sempre o mesmo: reduzir a sua autonomia política. O plano mexia também com a administração local e com as universidades, nas quais deveria ser privilegiado o ensino do direito real castelhano em detrimento do direito romano e canônico. Paralelamente, procedia-se a uma renovação significativa dos quadros dirigentes desses conselhos. Sem homens de confiança dispostos a seguir Macanaz, o plano não teria condições de ser implementado. As reformas tinham uma indispensável vertente social, que Francisco Precioso enfatiza e desconstrói. De resto, o autor faz a esse respeito um trabalho notável e muito pertinente para as ambições do estudo, procedendo ao levantamento dos ministros nomeados durante o "consulado" de Melchor. A ideia passava por saber quem eram esses homens, de que forma se relacionavam com Melchor e o que lhes aconteceu quando o fiscal geral caiu em desgraça.

O contexto político propício a grandes reformas terminou com a chegada da segunda mulher de Felipe V, Isabel de Farnesio, à corte espanhola, onde rapidamente se procedeu a uma purga dos elementos mais conotados com o regime anterior. Entre eles estava Macanaz, criticado muito especialmente por conta do protagonismo assumido no confronto que Madrid manteve com Roma. O seu célebre Pedimento fiscal do los cincuenta y cinco puntos deixava claras as intenções da coroa: estender o patronato real aos assuntos temporais que afetavam a Igreja, cerceando de permeio as imunidades e os privilégios fiscais do clero. O escrito encontrou inimigos poderosos, a começar pelo inquisidor-mor, Francesco del Giudice, e foi inclusivamente condenado pela Inquisição.

A perseguição de que foi alvo determinou o exílio de Macanaz na França e nos Países Baixos, onde atuou como espécie de diplomata informal de Felipe V por trinta anos. Francisco 
Precioso aproveita esse exílio para explorar os laços que persistiam entre Madri e as elites de origem castelhana dos territórios perdidos durante a guerra. A recuperação desses territórios, sobretudo na Itália, seria, de resto, uma das grandes prioridades diplomáticas de Felipe V e de sua mulher transalpina, a ponto de prejudicar outros compromissos no Império (Kuethe e Kenneth Andrien, 2014).

O capítulo 8, último desta parte do livro, é exclusivamente dedicado à ouevre de Melchor e ao seu pensamento, procurando-se interpretá-lo à luz dos desenvolvimentos culturais e intelectuais dos Setecentos. Não se trata propriamente de um exercício fácil, como a historiografia tem sublinhado: decantar sinais do progresso de valores e ideias associadas às Luzes em países católicos esbarra frequentemente na constatação de que houve uma convivência entre valores tradicionais e atitudes modernizadoras. Filosofia natural e teologia ou ciências exatas e religião não estavam permanentemente em estado de guerra. Assim, não espanta que se encontre no pensamento de Macanaz referências típicas da literatura reformista, algumas mais modernas e outras que seguiam uma formulação original bem antiga, como era o caso da defesa de monopólios comerciais - criação de companhias. Nele encontram-se também elementos que emergiram na cultura política portuguesa ao longo dos Setecentos, como era o caso da valorização do exemplo dos países do norte da Europa. É pena que Francisco Precioso não tenha procurado encontrar sinais de evolução no pensamento de Macanaz, sendo que a solução metodológica escolhida — análise detalhada de dois textos da lavra de Melchor, redigidos com vários anos de intervalo - até se prestava a isso. Já a confrontação com Feijoo parece ser particularmente eficaz, mostrando os limites das propostas reformadoras de Macanaz, que não ultrapassavam o absolutismo administrativo e institucional. Por isso, o autor insiste, com muita razão, na distinção que se deve estabelecer entre Macanaz e Campomanes ou Floriblanca.

A terceira parte da obra, dedicada à construção da memória de Melchor Macanaz, constitui um dos pontos altos do estudo. O processo é longo, estendendo-se por todo o século XVIII e entrando mesmo no século XIX, mas foi desencadeado pelo próprio Macanaz em 1739, quando, ainda durante o seu exílio, escreveu uma autobiografia. Por si só, isso revelava uma consciência bem apurada do seu papel na história da Espanha. Macanaz procurava então reabilitar-se na Corte, lembrando a injustiça de sua perseguição às mãos da Inquisição. Foi também uma oportunidade de recordar seus serviços à Monarquia e clarificar as intenções de seus muitos escritos e memoriais. O compromisso com o regalismo era naturalmente enfatizado. De resto, na identificação do ex-fiscal com o regalismo estaria a semente de sua recuperação subsequente às mãos de Gregorio Mayans y Siscar e de seu grupo. O conhecido erudito, que manteve correspondência com Macanaz, teria um papel decisivo na reconstrução da imagem deste, reapropriado como um autêntico herói injustiçado e perseguido por conta de sua fidelidade ao rei.

O processo de reconstrução da memória do antigo ministro de Felipe $V$ conheceria novos desenvolvimentos já no fim dos Setecentos, quando chegou a um público mais vasto. O editor 
do Semanario Erudito, um periódico dedicado à publicação de autores espanhóis do Siglo de Oro e do início do século XVIII, não foi imune ao fascínio que aquela grande referência do reformismo bourbônico começava a exercer. Entre 1787 e 1791, Antonio Valladares de Sotomayor deu à estampa vários escritos de Melchor ou a ele atribuídos, que Francisco Precioso revisitou e cuja autenticidade em boa hora ajudou a desconstruir. Como o livro deixa claro, a atribuição de autoria desses textos a Melchor não era propriamente uma prática inocente ou irrelevante. Ela aponta para uma agenda política mais ou menos explícita. Tratava-se de tirar partido da já então reconhecida autoridade política de Macanaz para sancionar ou questionar decisões entretanto tomadas pela Monarquia. A publicação de um texto em que Macanaz teria supostamente defendido a abolição dos jesuítas é disso um bom exemplo.

A instrumentalização da memória de Melchor Macanaz prosseguiu nas décadas seguintes, servindo, por exemplo, para legitimar um sistema político centrado nas secretarias. Como Francisco Precioso nota, assiste-se inclusivamente a um esforço para apresentar as reformas do tempo de Floriblanca como um desdobramento das reformas de Felipe V e do seu ministro. As Cortes de 1812 e os jornais liberais, em especial, apropriaram-se igualmente do discurso político de Macanaz para legitimar o seu projeto político. O regalismo de Macanaz, formulado para a defesa do Estado Absoluto, era agora acomodado às exigências ideológicas, e só aparentemente inconciliáveis, do Estado Liberal e do Estado Nação.

A última parte da obra centra-se em Pedro Macanaz, neto de Melchor, que começou como agente diplomático de Floriblanca e que chegou a ministro de Fernando VII. A trajetória de Pedro Macanaz constitui uma janela de observação para a dinâmica política espanhola de fins dos Setecentos e início dos Oitocentos, tanto na frente doméstica como na frente internacional. É uma oportunidade de revisitar a burocracia das secretarias de Estado, completamente dominadas pelos respectivos secretários, ou a aproximação diplomática ao gigante do leste (Rússia).

A inclusão da vida de Pedro neste estudo cumpre, todavia, um propósito mais significativo. Ela serve para ilustrar as limitações da mobilidade social na Espanha moderna, e esse é o grande tema que Francisco Precioso quis abordar e discutir. A partir da sua base murciana de Hellín, Pedro, tal como o avô, construiu uma carreira política de grande sucesso à escala nacional. No entanto, e também como o avô, viu baldadas as esperanças de alcançar um patamar social superior, permanecendo no perímetro original da "gente média". Tal como Melchor, Pedro também acabou seus dias em sua vila natal de Hellín. De resto, a esfera local ou regional constituiria o espaço de implantação natural dessa "gente média", que raramente consolidaria posições à escala nacional. Os casos de Floriblanca ou Campomanes são sobretudo exceções que confirmam a regra. O projeto familiar dos Macanaz é, a esse respeito, particularmente desastroso, na medida em que foi incapaz de romper com a rigidez estamental da Espanha moderna, apesar de ter contado com duas figuras de primeiro plano na história política do país. 
Em síntese, esta é uma obra que se tornará fundamental para os interessados no reformismo político dos Setecentos. O livro tem, como todos, fragilidades. A mais grave é, sem dúvida, a inexistência de um índice alfabético ou onomástico. Como todos, também nos deixa por vezes a suspirar por mais. O fato de as reformas políticas terem sido ensaiadas a partir de uma instituição tradicional - Campomanes, por exemplo, também foi fiscal do Conselho de Castela —, e não necessariamente das modernas secretarias, era algo que gostaria de ver equacionado, assumidamente em prol de meus próprios interesses acadêmicos. A irrelevância da América no discurso de Macanaz é também algo que surpreende e que passa sem grande discussão. No entanto, nada disso belisca o mérito da obra aqui resenhada.

\section{Bibliografia}

DEDIEU, Jean-Pierre. Dinastía y elites de poder en el reinado de Felipe V. In: FERNÁNDEZ ALBALADEJO, Pablo Ed. Los Borbones: Dinastía y memoria de nación en la España del siglo XVIII. Madrid: Marcial PonsCasa Velázquez, 2002.

KUETHE, Allan; ANDRIEN, Kenneth. The Spanish Atlantic World in the Eighteenth Century: War and the
Bourbon Reforms (1713-1796). Nova York: Cambridge University Press, 2014.

MARTÍN GAITE, Carmen. Macanaz otro paciente de la Inquisición. Barcelona: Destino, 1982 (1968).

RUIZ TORRES, Pedro. Reformismo e Ilustración: Historia de España. Barcelona/Madrid: Crítica/Marcial Pons, 2008, v. 5. 